\title{
Inequality Between Whom? Patterns, Trends, and Implications of Horizontal Inequality in the Philippines
}

\author{
Omar Shahabudin McDoom ${ }^{1} \cdot$ Celia Reyes $^{2}(D) \cdot$ Christian Mina $^{2} \cdot$ Ronina Asis $^{2}$
}

Accepted: 18 February 2018 / Published online: 14 March 2018

(C) UNU-WIDER 2018, corrected publication February 2019

\begin{abstract}
An overall decline in inequality within a country, when assessed using nationallevel measures, can evidently obscure important variation in inequality at the subnational level. However, social planners face a choice, whose importance we argue is often underestimated, in deciding the appropriate spatial and social boundaries along which inequality should be measured at the local level. We illustrate the consequential nature of this choice by examining a historically unequal country that has experienced a recent overall decline in inequality at the national level. Drawing on census micro-data, we show the Philippines made impressive progress in reducing disparities in education and access to basic public services between 2000 and 2010. This change, however, appears less positive when inequality is measured at the subnational level using spatial and social boundaries selected for their socio-political significance in the Philippines context. Specifically, using measures of total, within-group and between-group inequality, we find important differences within and between three salient ethno-religious groupings-Muslims, indigenous persons, and everyone else-as well as within and between three major island groupings, Mindanao, Visayas, and Luzon. We consider the implication of one of these differences-variation in between-group inequality — by examining its correlation with social and political instability
\end{abstract}

The original version of this article was revised due to a retrospective Open Access order.

Omar Shahabudin McDoom

o.s.mcdoom@1se.ac.uk

Celia Reyes

creyes@mail.pids.gov.ph

Christian Mina

cmina@mail.pids.gov.ph

Ronina Asis

rasis@mail.pids.gov.ph

1 London School of Economics, London, UK

2 Philippine Institute for Development Studies, Quezon, Philippines 
at the subnational level. Our findings underscore the importance of examining inequality at appropriate localized levels of analysis and, specifically, selecting carefully the spatial and social boundaries along which it should be measured.

Keywords Horizontal inequality · Ethnic group - Indigenous people $\cdot$ Violent conflict · Philippines $\cdot$ Mindanao

\section{JEL Classification $\mathrm{J} 15 \cdot \mathrm{I} 24 \cdot \mathrm{D} 63 \cdot \mathrm{Z} 13$}

\section{Introduction}

Although inequality has become one of the defining political issues of the early twenty-first century-its reduction has become United Nations Sustainable Development Goal 10global income inequality has in fact been in decline for more than three decades. Between 1975 and 2010, the Gini coefficient, perhaps the most well-known measure of relative inequality, moved from 0.739 to 0.631 , based on the most comprehensive data on income inequality available globally (Niño-Zarazúa et al. 2017). Analysis at such a highly-aggregated level obviously obscures important differences between regions and countries. Inequality trends in North America differ dramatically from those in East Asia and the Pacific, for instance. Similarly, inequality patterns in China are starkly different from those in Japan. These differences are not only of normative concern; they may also have observable consequences. The "Occupy Movement" for example, originated in 2011 in New York City, arguably the world's financial center of gravity, and reportedly expanded to inspire protests in over 900 cities across 82 countries all around the world (Adam 2011).

In this article, we take the level of analysis one step lower and explore the significance of inequality patterns at the subnational level. National-level analysis can conceal meaningful subnational variation in the same manner as global and regional-level data may mask important country-level differences. The Philippines is a rising lower middle-income economy, noted for historically high levels of inequality (Kondo 2014), but whose income inequality has followed the global downward trend over the last two decades. From a peak of 0.5183 in 1997, the year of the Asian Financial Crisis, the Philippines' Gini coefficient has since monotonically declined from 0.5045 in 2000 to 0.4714 in 2012 (Reyes et al. 2012).

While such a redistribution of income may seem cause for celebration for advocates of social justice, we urge caution. We explore subnational patterns and trends in inequality within and across spatial and social boundaries in the Philippines. There has been scant research on inequality between socially-salient groups in particular in the Philippines and the country's social and geographic complexity presents a useful opportunity to illustrate the value of examining inequality at more localized levels of analysis. Our findings highlight the risks of reliance on measures aggregated at levels that may obscure inequality's consequences.

In analyzing subnational inequality we make two important conceptual choices. First, we focus on inequality of opportunity rather than inequality of outcome given the greater normative significance attached to disparities in life chances. Specifically, instead of income or wealth inequality, we examine indicators of education and access to basic services. Second, we measure inequality along subnational spatial and social boundaries purposely defined and selected for their socio-political significance. The consensus on the socially-constructed nature of ethnic identities (Chandra 2006) underscores the importance of considering carefully how groups should be categorized when measuring between-group disparities. Our findings confirm not only that there is substantial subnational variation 
between regions and social groups in inequality levels and trends but, furthermore, that these differences are cause for concern in the Philippines context.

Specifically, we examine inequality levels and trends first between and within the Philippines' three major island groupings each with distinct politico-historical trajectories: Mindanao, Visayas, and Luzon; and second, between and within three socially and politically salient ethno-religious blocs: Muslims, indigenous persons (who are not Muslims), and everyone else i.e. those who are neither Muslim nor an indigenous person. Our headline findings indicate that contrary to the overall favorable picture of inequality's decline at the national-level between 2000 and 2010, there are stark subnational differences between regions and ethnoreligious groups in levels and trends. More particularly, first, Mindanao has, by far, the highest levels of overall, within-group, and between-group inequality of the three island regions. Second, overall inequality levels improved in all three regions but much more significantly in Luzon and Visayas than in Mindanao, thus widening the gap between them. Third, betweengroup (horizontal) inequality improved in Luzon and to a lesser extent Visayas, but Mindanao became more unequal in almost all measured dimensions principally due to an increase in the gap between Muslims and indigenous persons on the one hand and everyone else on the other. Fourth, although Muslims and indigenous persons have the highest levels of withingroup inequality and lowest socio-economic scores at the national level, at the subnational level their situations vary with island region. Within-group inequality is high among Muslims in Mindanao and indigenous persons in Luzon where both groups are also at the bottom of the socio-economic hierarchy, but low among Muslims in Luzon and indigenous persons in Visayas respectively where their socio-economic status is also better.

We suggest these subnational differences, as well as others we enumerate later in the article, have observable consequences as well as implications for policy-makers in the Philippines. We illustrate the importance of these implications by considering one potential consequence of one of these differences: the impact of differences in levels of betweengroup inequality on the country's social and political stability. Our analysis suggests a strong association between horizontal inequality and stability. Specifically, Mindanao, which has the highest and also a worsening level of inequality between the three ethnoreligious groups, also has the highest incidence of events indicative of social and political instability among the three regions. Our analysis underscores the importance of further work on such subnational associations in the Philippines.

The article proceeds as follows. Section 2 explains the choices we make in conceptualizing inequality. Section 3 introduces the Philippines to the reader and reviews existing work on inequality in the country. Section 4 then describes the data and methods employed. Section 5 presents our findings, distinguishing between national and subnational-level results, and examining the association between horizontal inequality and socio-political stability. Section 6 concludes.

\section{Conceptualizing Inequality}

The rising importance of inequality in global political discourse at the start of the twentyfirst century has spurred interest in the debate over how to conceptualize inequality. Two questions have received considerable attention in this discussion. Inequality of what? And inequality between whom? In this article, we examine, first, inequality of opportunity rather than inequality of outcome and, second, inequality between socially salient groups rather than inequality between individuals or households. The latter concept is sometimes also referred to as horizontal inequality. We describe the theoretical logic advanced by each 
concept's principal proponents for why inequality of opportunity and horizontal inequality are important, and why we chose to examine them, along with working definitions used in the article.

The concept of inequality of opportunity has longstanding antecedents that reach back to Rawls' (1971) theory of justice, Sen's (1987) human capability approach, and Dworkin's (1981) idea of equality of resources, inter alia. The core idea is the importance attached to individual responsibility for achievements. Roemer (1998), building on this work, defined equality of opportunity in terms of "advantages" and distinguished between advantages attributable to an individual's "efforts" and advantages attributable to "circumstances" that are beyond her control. Equality of opportunity exists when advantages are attained independently of such circumstances. Inequality of opportunity then matters because it offends normative principles of social fairness. It is unfair to hold an individual responsible for an outcome that is beyond her power to influence. We focus then in the article on the features of a person's environment that affect life chances but for which the person is not unequivocally responsible. For these reasons, we examine inequality in education and access to basic services given their collective potential to shape life chances. Specifically, we look at years of schooling, literacy, and access to electricity, safe water, and sanitation. Table 1 provides technical definitions of these indicators.

The concept of horizontal inequality, introduced and developed principally by Stewart (2002) has importance for both normative and consequentialist reasons. Stewart and Langer (2006) defined it as "inequality among culturally defined (or constructed) groups, in contrast with vertical inequality (VI) which is inequality among households or individuals". Material differences between ethno-cultural groups that result, for instance, from historical disadvantages or contemporary prejudice and discrimination, raise normative concerns for fairness in society. But horizontal inequality is also believed to be important because it has observable adverse consequences. An ever-expanding body of empirical work has documented horizontal or between-group inequality's links with poor social integration (McDoom 2018), public goods under-provision (Baldwin and Huber 2010), democratic instability (Huber and Suryanarayan 2015), economic under-development (Stewart 2002), and with civil war and social conflict more generally (Cederman et al. 2013).

Stewart's definition of horizontal inequality also explicitly acknowledges the sociallyconstructed nature of ethno-cultural groups. We pay particular attention to this issue in operationalizing horizontal inequality as how best to define and categorize groups is not always obvious and the choice can be consequential (McDoom and Gisselquist 2016).

Table 1 Definition of indicators analyzed

\begin{tabular}{|c|c|}
\hline Indicator & Definition \\
\hline Schooling & Years of schooling if individual is aged 25 and over \\
\hline Literacy & $\begin{array}{l}1 \text { if an individual aged } 10 \text { and over is literate (or can both read and write a simple } \\
\text { message); } 0 \text { if illiterate }\end{array}$ \\
\hline Access to safe water & $\begin{array}{l}1 \text { if an individual belongs to a household having access to safe drinking water (or } \\
\text { if main source of drinking water supply is either community water system, tubed/ } \\
\text { piped well or bottled water); } 0 \text { otherwise }\end{array}$ \\
\hline Access to sanitation & $\begin{array}{l}1 \text { if an individual belongs to a household having access to a sanitary toilet facility (or } \\
\text { if type of toilet facility is either water-sealed sewer septic tank, other depository, or } \\
\text { closed pit); } 0 \text { otherwise }\end{array}$ \\
\hline Access to electricity & 1 if an individual belongs to a household having access to electricity; 0 otherwise \\
\hline
\end{tabular}


However, it is not only social boundaries that may be constructed. Spatial boundaries may also result from socio-historical processes. While formal spatial boundaries-for instance those that distinguish urban from rural areas or that define administrative regions-are commonly and conveniently employed in subnational analyses, we argue that these are not necessarily always the boundaries with the greatest salience if our objective is to understand inequality's consequences. For this reason, we consider spatial boundaries whose resonance with individuals and communities derives from how they identify and compare themselves geographically. In the context of the Philippines, the distinct historical trajectories behind the three major island groupings of Luzon, Visayas, and Mindanao suggest it may useful to explore inequality within and between them.

\section{The Philippines and Inequality}

\subsection{Case Background}

The distinct politico-historical significance of the Philippines' three major island groups reflects their distinct pre-colonial settlement patterns and subsequent colonial experiences. One critical juncture that helped shape these informal boundaries was the arrival of imperial Spain in the sixteenth century which concentrated its colonial resources first in Luzon and then in Visayas. Spanish conquest ensured Catholicism and an overarching Filipino identity would become dominant social forces in these two northern regions in marked contrast with Mindanao in the south, whose earlier contact with Islam in the fourteenth century, was central to resistance to Christianization and Filipinization (Majul 1988). This resistance would abate during the American colonial period (1898-1946) (Abinales 2010) and intensify in the post-colonial era (1946+) when an expanded resettlement program for migrants from Luzon and Visayas would exacerbate the dispossession and minoritization of Mindanao's native population. This marginalization would help motivate several armed rebellions from within the Muslim Moro communities (McKenna 1998) which the Philippines central government, established in Luzon, has not fully resolved as of today. It is for these reasons that subnational inequality patterns between and within these three island groups are valuable to examine in the Philippines context.

Demographically, the Philippines grew from 76.3 to 92.1 million individuals between 2000 and 2010. Broadly, more than half of these individuals are densely-concentrated in Luzon with nearly one quarter in Mindanao and one fifth in Visayas. The 2000 and 2010 Population Censuses, allowing self-identification, recorded 147 and 182 ethno-linguistic groups respectively as well as 93 and then 97 religious affiliations in the Philippines. The apparently significant increase in ethno-linguistic diversity recorded in just one decade underscores the constructed, fluid, and subjective nature of ethnic identity and the challenge of measuring it and for this reason, we re-classified this social complexity into a smaller number of groupings whose socio-political salience had proven more resilient in the longue durée. This approach, focusing purposely on only politically and/or socially relevant groups, has been practised by a number of ethnic politics specialists interested in estimating the effects of ethnic diversity and divisions in societies (Posner 2004; Birnir et al. 2015; Wucherpfennig et al. 2011). We consequently re-grouped the population into Muslims, indigenous persons (who were not Muslim), and everyone else. The longstanding salience of Muslim identity in the Philippines context reflects the historic conflict and resistance to incorporation into the modern Filipino state by Mindanao's Moro population. 
For indigenous communities, the socio-political significance of indigenous status is reflected in the institutions the modern Filipino state had established to protect their rights as well as the conflicts with competing private interests, particularly over ancestral lands and natural resources thereon, that these institutions then intensified.

Both Muslims and indigenous persons (non-Muslim) are minority groupings and represented approximately 5.5 and $8.6 \%$ of the overall Filipino population respectively in 2010. Muslims are overwhelmingly located in Mindanao where they represent nearly one fifth of its population and are concentrated principally in the Autonomous Region of Muslim Mindanao (ARMM). Indigenous persons, in contrast, are spread throughout all three regions with stronger concentrations in Luzon, primarily in the Cordillera Administrative Region (CAR), and Mindanao, primarily in upland and forest areas. Non-Muslim, nonindigenous persons represent an overall national majority, $86.0 \%$, as well as a majority in all three island groups. They also have the overall highest socio-economic status of the three groupings. Educationally for instance, non-Muslim, non-indigenous persons had received an average of 9.1 years of schooling and $98.7 \%$ were literate in 2010 . In contrast, Muslims and indigenous persons had received 6.1 and 7.3 years of schooling and had 85.3 and $92.8 \%$ literacy respectively. This hierarchy holds at the national level for the other three developmental indicators - access to safe water, sanitation, and electricity - that we analyzed, though Muslims had a slight advantage over indigenous persons on the latter two dimensions. Table 2 summarizes descriptive statistics at the national and subnational levels for each of the three groups and on each of the 5 development indicators examined. It is worth noting that, although Muslims remain the most educationally-disadvantaged grouping, they recorded the strongest percentage increase in schooling and literacy levels between 2000 and 2010 of the three groups. Further research would help establish whether this could be attributed to efforts, beginning in 2004, to align the madrassahs, Islamic religious schools, with the national educational system.

\subsection{Inequality in the Philippines}

Despite the stark differences between these groupings, and the socio-political significance of them, there has been surprisingly little research on between-group inequality in the Philippines. Much of the extant work examines national-level or spatial inequality between urban and rural areas or between different subnational administrative units. The focus has also been primarily on income or wealth inequality, and not inequality of opportunity. The findings are nonetheless worth reviewing here not least for their suggestions of inequality drivers in the Philippines context.

It is widely-recognized that the Philippines has had historically high levels of income and wealth inequality by global and regional standards. Land inequality in particular has been analyzed as an influential initial condition that has shaped the country's subsequent growth and poverty levels (Balisacan and Fuwa 2004). The origins of land inequality lie, in part, in the Spanish colonial conquest whose legacy includes the concentration of land in the hands of Filipinos of Spanish ancestry who in turn constitute an entrenched elite class generally opposed to land reform and who occupy a prominent position in the country's politics and business (Sidel 1999; McCoy 2009). A significant body of research has also highlighted the large and growing spatial inequalities in the Philippines. The urban-rural gap in particular is significant. Research has suggested urbanization, specifically the growing share of the population that lives in urban areas, accounts for the slight increase in national income inequality observed between 1991 and 2009 (an increase using Theil but 


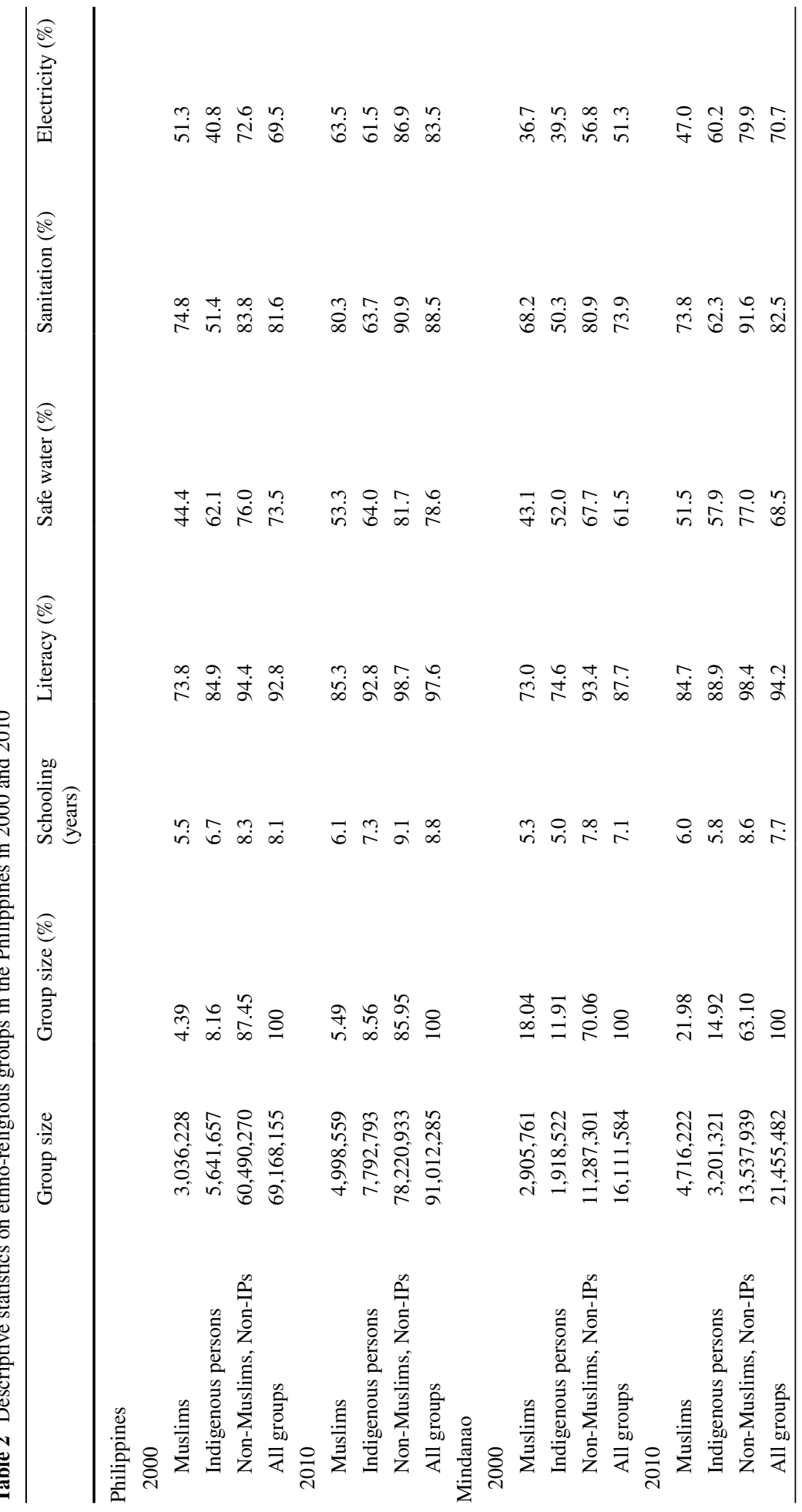




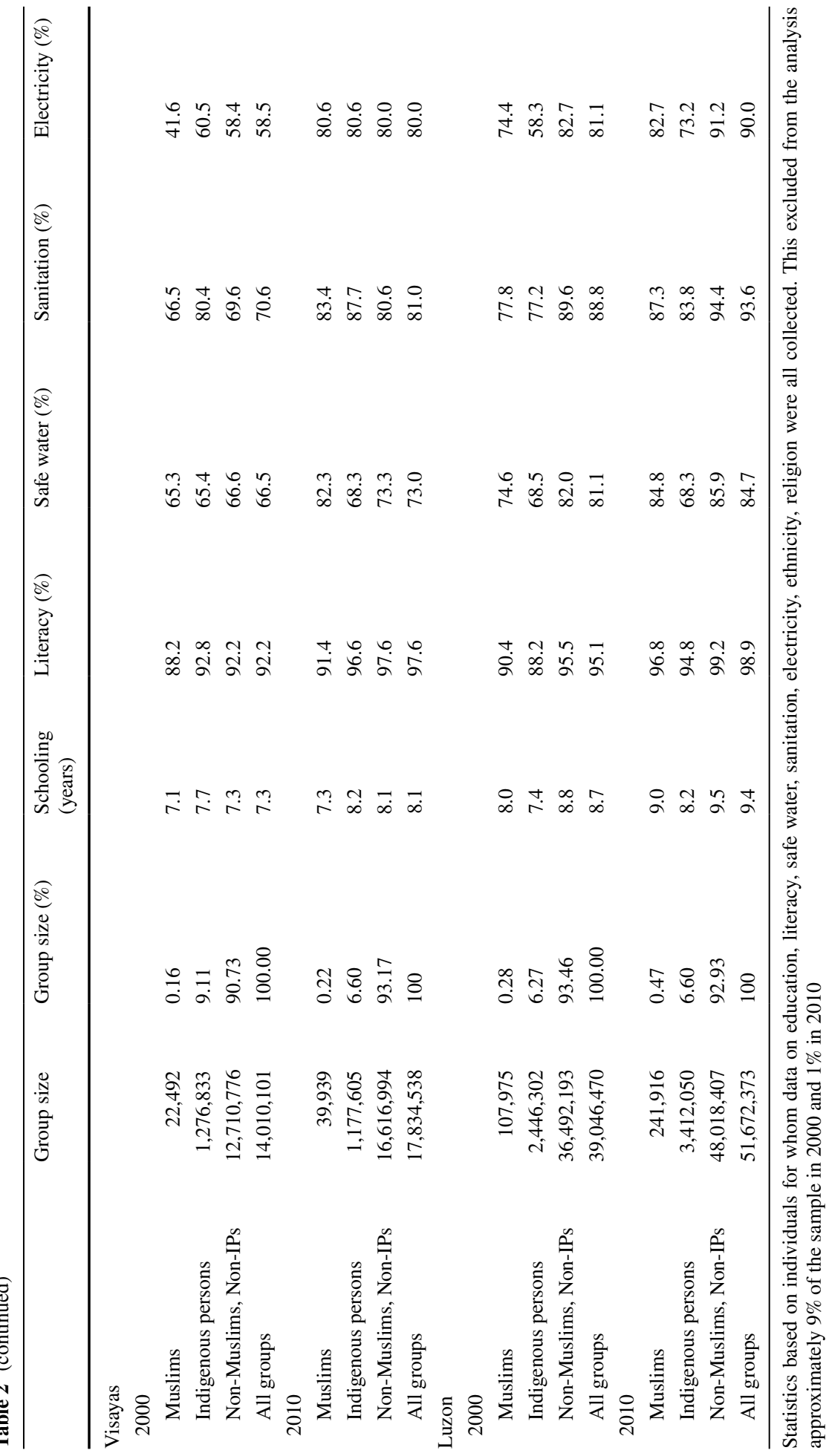


a decline using Gini). It has also found that while urban inequality has declined, rural inequality has increased (Kanbur and Zhuang 2013).

Research has also examined spatial inequality along subnational administrative boundaries, typically regions and provinces, and pointed to the growing disparity between the National Capital Region in Luzon and the rest of the country; or else between regions connected to the global economy, for instance coastal areas of Visayas with strong tourist industries or regions with Special Economic Zones on the one hand and rural hinterland or otherwise peripheral regions on the other (Clausen 2010). Globalization features prominently as an explanatory factor in this research (Akita and Pagulayan 2014; Clausen 2010) and one study has pointed specifically to international migration and the role of remittances from the large number of Filipinos working overseas in increasing income inequality (Edgard R. Rodriguez 1998). Individuals with the skills and training that enable them to take up employment opportunities abroad typically come from already highly-developed regions. Decentralization, often promoted as supportive of policies aimed at inequality reduction, has been found to have either, at best, no or an ambiguous effect on inequality in the Philippines (Akita and Pagulayan 2014; Hill 2008) or, at worst, a role in entrenching the power of local, often autocratic elites uninterested in redistribution (Sidel 2014).

In contrast, research on between-group inequality in the Philippines has been limited. McDoom and Gisselquist (2016) documented patterns and trends in between-group inequality in Mindanao and also its role in inhibiting social integration there (McDoom 2018). However, there has been no research examining horizontal inequality's relationship with the many other adverse phenomena that research in other contexts has documented. Arguably the strongest consensus has formed in respect of its association with violent conflict (Østby 2008; Mancini 2005; Stewart 2010; Gubler and Selway 2012; Cederman et al. 2011; Murshed and Gates 2005) where the disparity between ethnic groups is believed to be a source of grievance that motivates rebellion against the state or violence between groups. Grievance also features strongly in descriptive accounts of the conflicts that have beset the Philippines, in particular the insurgencies waged by Moro rebel groups in Mindanao (McKenna 1998; Lara 2014; Gutierrez et al. 2000; Majul 1988). Accounts emphasize Moro resentment in several respects: their numerical minorization by settlers from Luzon and Visayas; their dispossession from lands they had historically controlled; their inferior socio-economic status vis-à-vis non-Muslim and non-indigenous communities; and the relatively limited resources allocated to areas they inhabit by the central government in Manila. This sentiment is exacerbated by the historical context in which the Moro had once been the politically and socially ascendant grouping in Mindanao. One implication of high and increasing between-group inequality to consider in the Philippines context then is its potential association with social and political stability.

\section{Data and Methods}

We draw on 10 and 20\% samples of the 2000 and 2010 Philippines Population and Housing Censuses respectively that provided individual-level data on roughly 7 and 20 million individuals. We examined 5 non-income indicators of inequality: (1) average years of schooling (among those aged 25 and over); (2) literacy status (among those aged 10 and over); (3) access to safe drinking water; (4) access to sanitary toilet facilities; (5) and access to electricity. We included only individuals for whom data on all 5 indicators and ethnicity were available. Our criterion excluded only $1 \%$ of the 2010 sample but $9 \%$ of the 2000 sample, suggesting higher data quality collection in 2010 . 
Importantly, ethnicity data were well-reported with only $1.1 \%$ missing in 2000 and $0.5 \%$ in 2010. Using these 5 indicators, we then measure total, within-group, and betweengroup inequality at the national and then at each of the three regional levels. Specifically, we calculate the Gini coefficient and Theil index for total and within-group inequality at national and subnational levels, and then the GGini, GTheil, and Grouped Coefficient of Variation (GCOV) for between-group inequality, again at the national and subnational levels. Each of the between-group inequality measures is calculated as follows.

$$
\text { GGini }=\frac{1}{2 \bar{y}} \sum_{r}^{R} \sum_{s}^{S} p_{r} p_{s}\left|\bar{y}_{r}-\bar{y}_{s}\right|,
$$

where $\bar{y}_{r}=\frac{1}{n_{r}} \sum_{i}^{n_{r}} \mathrm{y}_{i r}$ is group r's mean value; $R$ is group $r$ 's population size; $p_{r}$ is group $r$ 's population share; $\mathrm{y}_{i r}$ is the quantity of the variable of interest (e.g., years of education) of the $i$ th member of group $r$.

$$
\text { GTheil }=\sum_{r}^{R} p_{r} \frac{\bar{y}_{r}}{\bar{y}} \log \frac{\bar{y}_{r}}{\bar{y}},
$$

where $\bar{y}_{r}=\frac{1}{n_{r}} \sum_{i}^{n_{r}} \mathrm{y}_{i r}$ is group $r$ 's mean value; $R$ is group $r$ 's population size; $p_{r}$ is group r's population share; $y_{i r}$ is the quantity of the variable of interest (e.g., years of education) of the $i$ th member of group $r$.

$$
\mathrm{GCOV}=\frac{1}{\bar{y}}\left(\sum_{r}^{R} p_{r}\left(\left(\bar{y}_{r}-\bar{y}\right)^{2}\right)\right)^{\frac{1}{2}},
$$

where $\bar{y}_{r}=\frac{1}{n_{r}} \sum_{i}^{n_{r}} \mathrm{y}_{i r}$ is group $r$ 's mean value; $R$ is the number of groups; $p_{r}$ is group $r$ 's population share; $\mathrm{y}_{i r}$ is the quantity of the variable of interest (e.g., years of education) of the $i$ th member of group $r$.

We also examine the relationship between horizontal inequality and social and political instability in the Philippines. Horizontal inequality is measured for 2010 using a Gini coefficient calculated using all 5 non-income indicators described above that have been aggregated into an index using principal components analysis. Social and political instability is measured using data from the Philippines Office of Civil Defense that recorded incidents of organized armed attacks, individual grenade or bomb explosions, and displacements of individuals due to conflict throughout the country. We examined incidents that occurred between 2010 and 2013 to help disentangle the potentially endogenous relationship between horizontal inequality and political and social instability. The model specified controls for population size, land area, poverty levels, road density (indicative of the relative mobility of state and rebel forces), and the extent of school infrastructure (indicative of developmental levels). We also include location dummies for the three major island groups with Mindanao as the reference group. The exact definitions of the co-variates are provided in Table 3 along with their sources. We utilized Poisson regression given the count nature of the dependent variable and measured all variables at the municipality level. In 2010, the Philippines territorial hierarchy comprised 17 regions, 85 provinces, 1491 municipalities, and 42,025 barangays. 


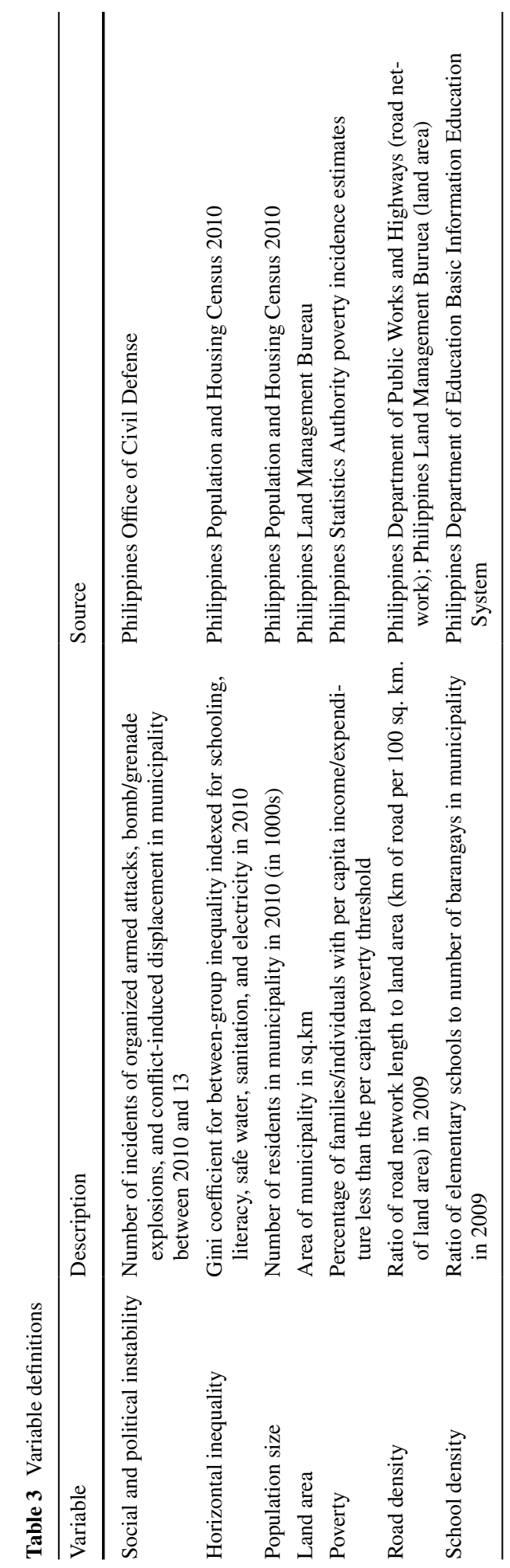




\section{Results}

\subsection{National-Level Analysis}

At the national level the data present a broadly positive portrait of non-income inequality in the Philippines. Total inequality in 2010, expressed as a Gini coefficient, does not exceed 0.24 on any of the 5 dimensions. The highest inequality is in schooling. It is worth noting that, in contrast with the Gini, the Theil index suggests inequality is higher in terms of access to services than in education, reflecting the higher sensitivity of the Gini to changes in the middle of the distribution. Decomposition analysis reveals that the contribution of within-group inequality - that is within the Muslims, indigenous persons, and non-Muslim, non-indigenous groupings - to total inequality greatly exceeds that of between-group inequality both in 2000 and 2010. However, caution should be exercised in interpreting the policy significance of this fact given the higher normative premium usually attached to between-group inequality as well as its potentially stronger adverse effects (Kanbur 2006). The trend is also favorable. Total inequality declined on all 5 dimensions between 2000 and 2010 with the strongest decline observed in access to electricity, likely reflecting investments in rural electrification made during the Arroyo administration (2001-10). Table 4 summarizes the findings in respect of total inequality.

Within-group inequality at the national level reveals important differences between groupings. Muslims have, by far, the highest within-group inequality on all 5 dimensions. It is at least twice as high on all dimensions in 2010 compared with non-Muslim, non-indigenous persons who have the lowest within-group inequality levels of all three groupings in 2000 and 2010. Sub-group analysis reveals an important divide within the Muslim grouping: Muslims who are also classified as indigenous persons are much less well-off than Muslims who are not, particularly in respect of education levels. Tellingly, indigenous Muslims are also less well-off than indigenous non-Muslims. Being Muslim and being indigenous then is a double disadvantage. As with total inequality, the trend in within-group inequality is also favourable. It declined between 2000 and 2010 for all three groupings. However, disparities again exist between them. Indigenous persons had the smallest percentage decline on 4 dimensions and non-Muslim, non-indigenous persons the largest relative decrease on all 5 dimensions. Table 5 summarizes the findings in respect of within-group inequality.

Between-group inequality presents a slightly less positive picture at the national level. Scores are of similar magnitude on almost on all dimensions except literacy where the disparities between groups are less pronounced. This is true for all three measures employed: GTheil, GGini, and GCOV. The between-group inequality scores reflect the much lower socio-economic status, described earlier, that Muslims and indigenous persons possess compared with everyone else. Muslims had ranked last for schooling, literacy, and safe water access and indigenous persons for sanitation and electricity access in 2010. In contrast with total and within-group inequality, between-group inequality's trend is not upward across all 5 dimensions. It in fact worsened in respect of schooling and safe water when measured by GCOV and GGini. The trend data, however, are not unambiguous as the GTheil suggests these dimensions improved. Literacy showed the strongest relative improvement, reflecting perhaps the attempt to mainstream the national curriculum in private Islamic schools, or madrassahs. Table 6 summarizes the findings in respect of between-group inequality. 
Table 4 Total inequality in the Philippines in 2000 and 2010

\begin{tabular}{|c|c|c|c|c|c|c|c|c|c|c|}
\hline & \multicolumn{2}{|c|}{ Schooling } & \multicolumn{2}{|c|}{ Literacy } & \multicolumn{2}{|c|}{$\begin{array}{l}\text { Safe water } \\
\text { access }\end{array}$} & \multicolumn{2}{|c|}{$\begin{array}{l}\text { Sanitation } \\
\text { access }\end{array}$} & \multicolumn{2}{|c|}{$\begin{array}{l}\text { Electricity } \\
\text { access }\end{array}$} \\
\hline & 2000 & 2010 & 2000 & 2010 & 2000 & 2010 & 2000 & 2010 & 2000 & 2010 \\
\hline \multicolumn{11}{|l|}{ Philippines } \\
\hline \multicolumn{11}{|l|}{ Theil } \\
\hline Within-group & 0.135 & 0.110 & 0.073 & 0.024 & 0.301 & 0.235 & 0.198 & 0.119 & 0.353 & 0.175 \\
\hline Between-group & 0.004 & 0.004 & 0.001 & 0.001 & 0.005 & 0.005 & 0.004 & 0.003 & 0.008 & 0.005 \\
\hline Total & 0.138 & 0.114 & 0.074 & 0.025 & 0.307 & 0.241 & 0.202 & 0.122 & 0.361 & 0.181 \\
\hline \multicolumn{11}{|l|}{ Gini } \\
\hline Within-group & 0.210 & 0.183 & 0.045 & 0.010 & 0.191 & 0.144 & 0.129 & 0.071 & 0.221 & 0.104 \\
\hline Between-group & 0.025 & 0.027 & 0.016 & 0.011 & 0.031 & 0.034 & 0.024 & 0.024 & 0.040 & 0.035 \\
\hline Overlap & 0.039 & 0.035 & 0.011 & 0.003 & 0.042 & 0.036 & 0.030 & 0.019 & 0.043 & 0.026 \\
\hline Total & 0.275 & 0.244 & 0.072 & 0.024 & 0.264 & 0.214 & 0.183 & 0.114 & 0.303 & 0.165 \\
\hline \multicolumn{11}{|l|}{ Mindanao } \\
\hline \multicolumn{11}{|l|}{ Theil } \\
\hline Within-group & 0.189 & 0.167 & 0.125 & 0.058 & 0.469 & 0.364 & 0.285 & 0.181 & 0.646 & 0.329 \\
\hline Between-group & 0.015 & 0.014 & 0.005 & 0.002 & 0.014 & 0.014 & 0.014 & 0.012 & 0.014 & 0.017 \\
\hline Total & 0.204 & 0.181 & 0.131 & 0.060 & 0.483 & 0.378 & 0.299 & 0.192 & 0.660 & 0.347 \\
\hline \multicolumn{11}{|l|}{ Gini } \\
\hline Within-group & 0.174 & 0.146 & 0.045 & 0.015 & 0.192 & 0.129 & 0.116 & 0.056 & 0.254 & 0.115 \\
\hline Between-group & 0.074 & 0.076 & 0.046 & 0.030 & 0.074 & 0.080 & 0.071 & 0.073 & 0.075 & 0.088 \\
\hline Overlap & 0.081 & 0.085 & 0.031 & 0.012 & 0.117 & 0.105 & 0.071 & 0.045 & 0.154 & 0.089 \\
\hline Total & 0.329 & 0.307 & 0.123 & 0.057 & 0.383 & 0.313 & 0.259 & 0.174 & 0.484 & 0.292 \\
\hline \multicolumn{11}{|l|}{ Visayas } \\
\hline \multicolumn{11}{|l|}{ Theil } \\
\hline Within-group & 0.170 & 0.141 & 0.081 & 0.025 & 0.407 & 0.315 & 0.347 & 0.210 & 0.535 & 0.222 \\
\hline Between-group & 0.000 & 0.000 & 0.000 & 0.000 & 0.000 & 0.000 & 0.001 & 0.000 & 0.000 & 0.000 \\
\hline Total & 0.170 & 0.141 & 0.081 & 0.025 & 0.407 & 0.315 & 0.348 & 0.210 & 0.535 & 0.222 \\
\hline \multicolumn{11}{|l|}{ Gini } \\
\hline Within-group & 0.258 & 0.247 & 0.065 & 0.021 & 0.277 & 0.234 & 0.248 & 0.169 & 0.340 & 0.174 \\
\hline Between-group & 0.005 & 0.001 & 0.001 & 0.001 & 0.002 & 0.004 & 0.013 & 0.005 & 0.003 & 0.000 \\
\hline Overlap & 0.049 & 0.035 & 0.012 & 0.003 & 0.056 & 0.031 & 0.033 & 0.016 & 0.066 & 0.025 \\
\hline Total & 0.312 & 0.282 & 0.078 & 0.024 & 0.335 & 0.270 & 0.294 & 0.190 & 0.415 & 0.200 \\
\hline \multicolumn{11}{|l|}{ Luzon } \\
\hline \multicolumn{11}{|l|}{ Theil } \\
\hline Within-group & 0.101 & 0.079 & 0.050 & 0.011 & 0.209 & 0.164 & 0.118 & 0.065 & 0.206 & 0.104 \\
\hline Between-group & 0.001 & 0.001 & 0.000 & 0.000 & 0.001 & 0.001 & 0.001 & 0.000 & 0.003 & 0.001 \\
\hline Total & 0.102 & 0.080 & 0.051 & 0.011 & 0.209 & 0.166 & 0.118 & 0.066 & 0.209 & 0.106 \\
\hline \multicolumn{11}{|l|}{ Gini } \\
\hline Within-group & 0.206 & 0.177 & 0.040 & 0.007 & 0.160 & 0.125 & 0.092 & 0.050 & 0.156 & 0.078 \\
\hline Between-group & 0.009 & 0.008 & 0.005 & 0.003 & 0.010 & 0.013 & 0.009 & 0.007 & 0.018 & 0.013 \\
\hline Overlap & 0.022 & 0.020 & 0.005 & 0.001 & 0.019 & 0.015 & 0.011 & 0.007 & 0.015 & 0.010 \\
\hline Total & 0.237 & 0.204 & 0.049 & 0.011 & 0.189 & 0.153 & 0.112 & 0.064 & 0.189 & 0.100 \\
\hline
\end{tabular}


Table 5 Within-group inequality in the Philippines in 2000 and 2010

\begin{tabular}{|c|c|c|c|c|c|c|c|c|c|c|}
\hline & \multicolumn{2}{|c|}{ Schooling } & \multicolumn{2}{|c|}{ Literacy } & \multicolumn{2}{|c|}{$\begin{array}{l}\text { Safe water } \\
\text { access }\end{array}$} & \multicolumn{2}{|c|}{$\begin{array}{l}\text { Sanitation } \\
\text { access }\end{array}$} & \multicolumn{2}{|c|}{$\begin{array}{l}\text { Electricity } \\
\text { access }\end{array}$} \\
\hline & 2000 & 2010 & 2000 & 2010 & 2000 & 2010 & 2000 & 2010 & 2000 & 2010 \\
\hline \multicolumn{11}{|l|}{ Philippines } \\
\hline \multicolumn{11}{|l|}{ Gini } \\
\hline Muslims & 0.479 & 0.431 & 0.262 & 0.147 & 0.552 & 0.467 & 0.482 & 0.363 & 0.587 & 0.385 \\
\hline Indigenous persons & 0.356 & 0.337 & 0.151 & 0.072 & 0.377 & 0.360 & 0.250 & 0.197 & 0.484 & 0.365 \\
\hline Non-Muslims, Non-IPs & 0.258 & 0.226 & 0.056 & 0.013 & 0.239 & 0.183 & 0.162 & 0.091 & 0.272 & 0.131 \\
\hline \multicolumn{11}{|l|}{ Theil } \\
\hline Muslims & 0.451 & 0.362 & 0.304 & 0.159 & 0.802 & 0.628 & 0.657 & 0.450 & 0.883 & 0.486 \\
\hline Indigenous persons & 0.238 & 0.212 & 0.163 & 0.075 & 0.473 & 0.446 & 0.288 & 0.220 & 0.661 & 0.453 \\
\hline Non-Muslims, Non-IPs & 0.119 & 0.095 & 0.057 & 0.013 & 0.273 & 0.202 & 0.176 & 0.095 & 0.317 & 0.141 \\
\hline \multicolumn{11}{|l|}{ Mindanao } \\
\hline \multicolumn{11}{|l|}{ Gini } \\
\hline Muslims & 0.488 & 0.441 & 0.270 & 0.153 & 0.564 & 0.485 & 0.493 & 0.377 & 0.599 & 0.398 \\
\hline Indigenous persons & 0.432 & 0.393 & 0.254 & 0.111 & 0.477 & 0.421 & 0.315 & 0.262 & 0.629 & 0.530 \\
\hline Non-Muslims, Non-IPs & 0.274 & 0.249 & 0.066 & 0.016 & 0.321 & 0.230 & 0.189 & 0.084 & 0.429 & 0.201 \\
\hline \multicolumn{11}{|l|}{ Theil } \\
\hline Muslims & 0.468 & 0.377 & 0.314 & 0.166 & 0.830 & 0.663 & 0.678 & 0.472 & 0.913 & 0.507 \\
\hline Indigenous persons & 0.359 & 0.287 & 0.293 & 0.117 & 0.648 & 0.546 & 0.377 & 0.304 & 0.991 & 0.755 \\
\hline Non-Muslims, Non-IPs & 0.131 & 0.111 & 0.068 & 0.016 & 0.386 & 0.262 & 0.209 & 0.088 & 0.560 & 0.224 \\
\hline \multicolumn{11}{|l|}{ Visayas } \\
\hline \multicolumn{11}{|l|}{ Gini } \\
\hline Muslims & 0.314 & 0.343 & 0.118 & 0.086 & 0.346 & 0.177 & 0.335 & 0.166 & 0.584 & 0.194 \\
\hline Indigenous persons & 0.298 & 0.284 & 0.072 & 0.034 & 0.346 & 0.317 & 0.196 & 0.123 & 0.395 & 0.194 \\
\hline Non-Muslims, Non-IPs & 0.314 & 0.282 & 0.078 & 0.024 & 0.334 & 0.267 & 0.304 & 0.194 & 0.416 & 0.200 \\
\hline \multicolumn{11}{|l|}{ Theil } \\
\hline Muslims & 0.179 & 0.233 & 0.125 & 0.090 & 0.425 & 0.195 & 0.408 & 0.182 & 0.875 & 0.216 \\
\hline Indigenous persons & 0.157 & 0.149 & 0.074 & 0.034 & 0.424 & 0.380 & 0.218 & 0.131 & 0.503 & 0.216 \\
\hline Non-Muslims, Non-IPs & 0.171 & 0.141 & 0.082 & 0.024 & 0.405 & 0.311 & 0.362 & 0.216 & 0.538 & 0.223 \\
\hline \multicolumn{11}{|l|}{ Luzon } \\
\hline \multicolumn{11}{|l|}{ Gini } \\
\hline Muslims & 0.291 & 0.235 & 0.096 & 0.032 & 0.254 & 0.152 & 0.222 & 0.127 & 0.256 & 0.173 \\
\hline Indigenous persons & 0.321 & 0.294 & 0.118 & 0.052 & 0.315 & 0.317 & 0.228 & 0.162 & 0.417 & 0.268 \\
\hline Non-Muslims, Non-IPs & 0.231 & 0.198 & 0.045 & 0.008 & 0.180 & 0.141 & 0.104 & 0.056 & 0.173 & 0.088 \\
\hline \multicolumn{11}{|l|}{ Theil } \\
\hline Muslims & 0.170 & 0.117 & 0.100 & 0.033 & 0.293 & 0.165 & 0.251 & 0.136 & 0.295 & 0.189 \\
\hline Indigenous persons & 0.195 & 0.166 & 0.125 & 0.053 & 0.378 & 0.381 & 0.259 & 0.177 & 0.539 & 0.312 \\
\hline Non-Muslims, Non-IPs & 0.096 & 0.074 & 0.046 & 0.008 & 0.199 & 0.152 & 0.109 & 0.058 & 0.190 & 0.092 \\
\hline
\end{tabular}

\subsection{Subnational Analysis}

The portrait of inequality in the Philippines becomes more troubling when the data are disaggregated. In terms of total inequality, important differences between the three island 
Table 6 Between-group inequality in the Philippines in 2000 and 2010

\begin{tabular}{|c|c|c|c|c|c|c|c|c|c|c|}
\hline & \multicolumn{2}{|c|}{ Schooling } & \multicolumn{2}{|c|}{ Literacy } & \multicolumn{2}{|c|}{ Safe water access } & \multicolumn{2}{|c|}{$\begin{array}{l}\text { Sanitation } \\
\text { access }\end{array}$} & \multicolumn{2}{|c|}{ Electricity access } \\
\hline & 2000 & 2010 & 2000 & 2010 & 2000 & 2010 & 2000 & 2010 & 2000 & 2010 \\
\hline \multicolumn{11}{|c|}{ Philippines } \\
\hline GGini & 0.0250 & 0.0270 & 0.0160 & 0.0110 & 0.0310 & 0.0340 & 0.0240 & 0.0240 & 0.0400 & 0.0350 \\
\hline GTheil & 0.0036 & 0.0039 & 0.0014 & 0.0006 & 0.0055 & 0.0054 & 0.0040 & 0.0031 & 0.0082 & 0.0055 \\
\hline GCOV & 0.0852 & 0.0989 & 0.0514 & 0.0386 & 0.0967 & 0.1089 & 0.0841 & 0.0837 & 0.1216 & 0.1062 \\
\hline \multicolumn{11}{|c|}{ Mindanao } \\
\hline GGini & 0.0740 & 0.0760 & 0.0460 & 0.0300 & 0.0740 & 0.0800 & 0.0710 & 0.0730 & 0.0750 & 0.0880 \\
\hline GTheil & 0.0146 & 0.0142 & 0.0054 & 0.0020 & 0.0136 & 0.0140 & 0.0135 & 0.0117 & 0.0139 & 0.0173 \\
\hline GCOV & 0.1691 & 0.1781 & 0.1020 & 0.0682 & 0.1597 & 0.1781 & 0.1590 & 0.1618 & 0.1647 & 0.1840 \\
\hline \multicolumn{11}{|l|}{ Visayas } \\
\hline GGini & 0.0050 & 0.0010 & 0.0010 & 0.0010 & 0.0020 & 0.0040 & 0.0130 & 0.0050 & 0.0030 & 0.0000 \\
\hline GTheil & 0.0001 & 0.00001 & 0.0000 & 0.00001 & 0.00001 & 0.0002 & 0.0009 & 0.0002 & 0.0001 & 0.0000 \\
\hline GCOV & 0.0163 & 0.0053 & 0.0026 & 0.0041 & 0.0061 & 0.0179 & 0.0441 & 0.0217 & 0.0152 & 0.0018 \\
\hline \multicolumn{11}{|l|}{ Luzon } \\
\hline GGini & 0.0090 & 0.0080 & 0.0050 & 0.0030 & 0.0100 & 0.0130 & 0.0090 & 0.0070 & 0.0180 & 0.0130 \\
\hline GTheil & 0.0008 & 0.0006 & 0.0002 & 0.0001 & 0.00087 & 0.0014 & 0.0006 & 0.0004 & 0.0029 & 0.0013 \\
\hline GCOV & 0.0395 & 0.0353 & 0.0188 & 0.0112 & 0.0368 & 0.0506 & 0.0334 & 0.0284 & 0.0760 & 0.0498 \\
\hline
\end{tabular}

groups become apparent. Mindanao has, by far, the highest level of total inequality on all 5 non-income dimensions. In 2010, the Gini coefficient for Mindanao was 0.307 for schooling, for instance, but only 0.204 for Luzon. Luzon had the lowest levels of total inequality on all dimensions. The picture darkens further when one remembers the descriptive statistics confirm Mindanao is already the most under-developed and Luzon the most-developed of the three island groups. Although the trend is upward in all three regions, Mindanao lags behind, registering the smallest improvement in the Gini coefficient on all 5 dimensions between 2000 and 2010. The gap in total inequality between Mindanao and the rest of the country then widened in the intervening decade.

Within-group inequality patterns at the subnational level also challenge the narrative suggested by the national-level data. To begin with, contrary to their overall situation at the national-level, Muslims do not have the highest within-group inequality across all three island groups. Only in Mindanao is within-group inequality higher for Muslims than the other two groups. In Luzon and Visayas, Muslims in fact rank second in terms of withingroup inequality. To take education as an example, the Theil index indicated inequality among Muslims in Mindanao was 0.377 in 2010 but only 0.232 and 0.170 in Visayas and Luzon respectively. This is consistent with the descriptive statistics. Muslims in Luzon are much better-off than Muslims in Mindanao. Taking education again, Muslims in Luzon had an average of 9 years of schooling compared with only 6 years for Muslims in Mindanao. Consistent with the national level analysis, however, the trend in within-group inequality is upwards for Muslims across all three island groups between 2000 and 2010 on almost every dimension.

Perceptions of the position of indigenous persons also change when within-group is examined at the subnational level. While they have the highest within-group inequality in Luzon and rank second in Mindanao, they have the lowest within-group inequality of 
all three groupings in Visayas. The descriptive statistics shed further light on differences between island groups in the position of indigenous persons. While they have the lowest scores in Luzon on 5 dimensions, they have the highest scores on 4 dimensions in Visayas. However, this is relative to the other two groups. In absolute terms, the situation of indigenous persons is broadly similar in Luzon and Visayas. It is only in Mindanao that a discrepancy becomes apparent where indigenous persons are much worse off than indigenous communities in the other two island groups. Taking education again, the average indigenous person in Mindanao had received 5.8 years of schooling compared with 8.2 years in both Luzon and Visayas. As with Muslims, the trend in inequality among indigenous person was also positive between 2000 and 2010 across all three island groups, again consistent with the overall national-level trend.

It is in respect of between-group inequality that the risks of reliance on national-level measures become most apparent. An important difference exists between the three island groups with Mindanao again the outlier. Between-group inequality was several times higher in Mindanao than in Luzon and Visayas on all dimensions in 2010. Between-group inequality was roughly 0.17 in Mindanao on all dimensions, except literacy which was lower, when measured by GCOV. In contrast, in Luzon and Visayas between-group inequality values were an order of magnitude smaller on these same dimensions. For instance, between-group inequality in education in Mindanao was 0.1781 in 2010 but only 0.0053 and 0.0353 in Visayas and Luzon respectively. These differences are not solely explained by differences in the size of the three ethno-religious blocs in each island group. NonMuslim, non-indigenous persons represented between 87,91 , and $93 \%$ of the population in Mindanao, Visayas, and Luzon respectively. The largest driver remains the disparity in the situation of Muslims and indigenous persons on the one hand and everyone else on the other. This disparity is much greater in Mindanao than in the other two island groups as the descriptive statistics corroborate. Furthermore, the picture worsens when we examine the trend data. Consistent with the national-level trend, between-group inequality improved in Luzon and Visayas between 2000 and 2010 on most of the dimensions. However, contrary to this trend, Mindanao's between-group inequality scores worsened on all dimensions except literacy in the intervening decade. Not only is between-group inequality higher in Mindanao than anywhere else, the disparities between the three ethno-religious blocs have also gotten worse.

\subsection{Between-Group Inequality and Socio-political Instability}

Consistent with the theorized prediction we find a substantively and statistically significant association between horizontal inequality and socio-political instability at the subnational level. The relationship is positive. As disparities between the three ethno-religious groups increase, instability also increases. More precisely, the interpretation of the incidence rate ratios we report in Table 7 is as follows: a one unit increase in between-group inequality increases the rate of instability incidents by $9.7 \%$, holding all other variables constant. It is important to note that the location dummies highlight the distinctive situation of Mindanao. Not being in Luzon or Visayas i.e. being present in Mindanao increases the incident rate by over $900 \%$. Overwhelmingly, socio-political instability is concentrated in Mindanao which also has, by far, the highest level of between-group inequality of the three regions. Evidently, horizontal inequality is not the only potential driver of instability. We also find statistically significant positive associations with population size, land area, and poverty. As these increase, so too does instability. In contrast, road and school density decrease the 
Table 7 Predictors of sociopolitical instability at subnational level in the Philippines

\begin{tabular}{lll}
\hline Variable & Incidence rate ratio & Standard error \\
\hline Horizontal inequality & $1.0971^{* * *}$ & 0.0245 \\
Population size & $1.0008^{*}$ & 0.0004 \\
Land area & $0.9993^{* *}$ & 0.0003 \\
Poverty & $1.0000^{* * *}$ & 0.0000 \\
Road density & $0.9935^{* *}$ & 0.0023 \\
School density & $0.4754^{*}$ & 0.1417 \\
Luzon dummy & $0.0997 * * *$ & 0.0276 \\
Visayas dummy & $0.1050^{* * *}$ & 0.0348 \\
Constant & 0.7254 & 0.2426 \\
$N$ & 1620 & \\
Pseudo- $R^{2}$ & 0.34 & \\
\hline
\end{tabular}

Results estimated using Poisson regression; statistical significance $* p<0.05 ; * * p<0.01 ; * * * p<0.001$

rate of instability incidents. Their interpretation is not unequivocal. On the one hand, they may indicate a municipality's level of infrastructural development. More highly-developed municipalities are less likely to experience instability. On the other hand, road density may also indicate the feasibility of insurgent attacks. In municipalities where roads are extensive, it is relatively easy for the state to project its coercive power as it facilitates the mobility of police and military forces. Such municipalities are also likely to be unsuitable for guerrilla tactics.

\section{Conclusion}

Our findings underscore the importance of localized analysis of inequality and in particular the challenge facing researchers of choosing the appropriate spatial and social boundaries along which inequality should be examined. The choice is crucial if the objective is to help policy-makers decide what type of intervention, if any, is required to mitigate inequality's potentially adverse consequences. We selected geographic areas and social groups based on our judgement of their socio-political significance in the Philippines context. In making this judgement we considered how resilient to the passage of time these boundaries had been, indicated for example by the persistence of conflict and violence along them, and also the extent to which they had been formally institutionalized. To our knowledge, this is the first time between-group inequality has been analysed in the Philippines using these particular social groupings. Our work highlights the distinctiveness of Mindanao, as one of the three geographic areas examined, and the subordinate position of Muslims and indigenous persons in particular, as two of the three social groups considered. However, it also finds that the situation of Muslims and indigenous persons varies with region. It is not as problematic in Luzon and Visayas as it is in Mindanao.

Our choice of spatial and social boundaries is evidently not beyond criticism. We are keenly aware there exists, for instance, considerable sub-group diversity among Muslims, indigenous peoples, and the residual 'everyone else' category that we have not examined. Area specialists may argue there exist within these three major groupings social boundaries of even greater socio-political significance that we have ignored. Similarly, within the 
three major island groups, important differences exist. The position of the National Capital Region compared with the Cordillera Administrative Region in Luzon and the Davao Region against the Autonomous Region of Muslim Mindanao in Mindanao make stark contrasts for example. It remains open for others to conduct research on inequality along boundaries they adjudge more salient.

The article also explored one implication of one of the subnational disparities identified. We focused on between-group inequality. The association we identified between horizontal inequality and socio-political instability is consistent with the mounting evidence linking it with civil conflict in a growing number of country contexts. We emphasize, however, that the approach we used does not permit causal inference. We readily acknowledge the possibility of other unobserved conflict drivers as well as the strong likelihood of a feedback loop between violence and inequality. Not only may between-group inequality motivate conflict, it may also be shaped by it. In the Philippines context, conflict-induced displacement may well be driving the socio-economic scores of Muslims and indigenous persons. Many such individuals have been concentrated in areas in which conflict is present and have been forced to migrate to areas where their status has become more marginal.

Finally, having documented the existence of worrisome patterns and trends in withingroup and between-group inequality at the subnational level in the Philippines, we believe a priority for future research will be to identify the drivers behind them with a view to helping social planners formulate appropriate redistributive policies. The literature suggests many possibilities but we highlight one debate whose resolution we believe particularly important. To what extent is this inequality the result of decisions and actions taken at the national level and to what extent is it the product of more local forces? In the Philippines context, both seem plausible. The arena for national-level politics is Luzon wherein a dynastic elite class operates primarily to protect their private interests. Mindanao and to a lesser extent Visayas are peripheral regions and have been historically under-represented in national-level politics. At the same time, patronage politics are prevalent at the local level and local political elites have a strong interest in preserving the asymmetric nature of social relations in their communities. The answer to this question is not inconsequential. Decentralization is commonly presented as one way to address center-periphery inequalities and a significant level of resources are consequently allocated to its promotion and implementation.

Acknowledgements The authors thank Maria Blesila D. Mondez and Arkin A. Arboneda for their research assistance; the Philippines National Commission on Indigenous People (NCIP) for their advice on ethnic classifications; and the Philippines Statistics Authority for providing the census data. All errors in the paper naturally are our own. Funding was provided by UNU-WIDER.

Open Access This book is licensed under the terms of the Creative Commons Attribution-NonCommercial-ShareAlike 3.0 IGO License (https://creativecommons.org/licenses/by-nc-sa/3.0/igo/), which permits any noncommercial use, sharing, adaptation, distribution, and reproduction in any medium or format, as long as you give appropriate credit to the UNU-WIDER, provide a link to the Creative Commons licence and indicate if changes were made. If you remix, transform, or build upon this book or a part thereof, you must distribute your contributions under the same licence as the original.

\section{References}

Abinales, P. N. (2010). Orthodoxy and history in the Muslim-Mindanao narrative, Mindanao studies. Quezon City: Ateneo de Manila University Press.

Adam, K. (2011). Occupy Wall Street protests continue worldwide. London: In The Washington Post. 
Akita, T., \& Pagulayan, M. S. (2014). Structucal changes and interregional income inequality in the Philippines, 1975-2009. Review of Urban \& Regional Development Studies, 26(2), 135-154. https://doi. org/10.1111/rurd.12024.

Baldwin, K., \& Huber, J. D. (2010). Economic versus cultural differences: Forms of ethnic diversity and public goods provision. American Political Science Review, 104(4), 644-662. https://doi.org/10.1017/ S0003055410000419.

Balisacan, A. M., \& Fuwa, N. (2004). Going beyond crosscountry averages: Growth, inequality and poverty reduction in the Philippines. World Development, 32(11), 1891-1907. https://doi.org/10.1016/j.world dev.2004.05.010.

Birnir, J. K., Wilkenfeld, J., Fearon, J. D., Laitin, D. D., Gurr, T. R., Brancati, D., et al. (2015). Socially relevant ethnic groups, ethnic structure, and AMAR. Journal of Peace Research, 52(1), 110-115. https://doi.org/10.1177/0022343314536915.

Cederman, L.-E., Gleditsch, K. S., \& Buhaug, H. (2013). Inequality, grievances, and civil war, Cambridge studies in contentious politics. New York, NY: Cambridge University Press.

Cederman, L.-E., Weidmann, N. B., \& Gleditsch, K. S. (2011). Horizontal inequalities and ethnonationalist civil war: A global comparison. American Political Science Review, 105(03), 478-495. https:// doi.org/10.1017/S0003055411000207.

Chandra, K. (2006). What is ethnic identity and does it matter? Annual Review of Political Science, 9 , $397-424$.

Clausen, A. (2010). Economic globalization and regional disparities in the Philippines. Singapore Journal of Tropical Geography, 31(3), 299-316. https://doi.org/10.1111/j.1467-9493.2010.00405.x.

Dworkin, R. (1981). What is equality? Part 2: Equality of resources. Philosophy \& Public Affairs, 10(4), 283-345.

Gubler, J. R., \& Selway, J. S. (2012). Horizontal inequality, crosscutting cleavages, and civil war. Journal of Conflict Resolution, 56(2), 206-232.

Gutierrez, E. U., Ahmad, A., Gonzales, F. L., Mercado, E. R., Rocamora, J., Vitug, M. D., et al. (2000). Rebels, warlords, and ulama : A reader on Muslim separatism and the war in southern Philippines, Reader on Muslim separatism and the war in southern Philippines. Quezon City: Institute for Popular Democracy.

Hill, H. (2008). Globalization, inequality, and local-level dynamics: Indonesia and the Philippines*. Asian Economic Policy Review, 3(1), 42-61. https://doi.org/10.1111/j.1748-3131.2008.00087.x.

Huber, J. D., \& Suryanarayan, P. (2015). Ethnic inequality and the ethnification of political parties: Evidence from India. World Politics, 68(1), 149-188. https://doi.org/10.1017/S0043887115000349.

Kanbur, R. (2006). The policy significance of inequality decompositions. The Journal of Economic Inequality, 4(3), 367-374. https://doi.org/10.1007/s10888-005-9013-5.

Kanbur, R., \& Zhuang, J. (2013). Urbanization and Inequality in Asia. Asian Development Review, 30(1), 131-147. https://doi.org/10.1162/ADEV_a_00006.

Kondo, M. (2014). The Philippines: Inequality-trapped capitalism. Oxford: Oxford University Press.

Lara, F. (2014). Insurgents, clans, and states: Political legitimacy and resurgent conflict in Muslim Mindanao, Philippines. Quezon City: Ateneo de Manila University Press.

Majul, C. A. (1988). The Moro struggle in the Philippines. Third World Quarterly, 10(2), 897-922. https ://doi.org/10.1080/01436598808420087.

Mancini, L. (2005). Horizontal inequality and communal violence: Evidence from Indonesian districts. CRISE Working Paper No. 22.

McCoy, A. W. (2009). An anarchy of families: State and family in the Philippines. Vol. New perspectives in Southeast Asian studies. Madison, Wis: University of Wisconsin Press.

McDoom, O. S. (2018). Ethnic inequality, cultural distance, and social integration: Evidence from a native-settler conflict in the Philippines. Journal of Ethnic and Migration Studies. https://doi. org/10.1080/1369183x.2018.1427566.

McDoom, O. S., \& Gisselquist, R. M. (2016). The measurement of ethnic and religious divisions: Spatial, temporal, and categorical dimensions with evidence from Mindanao, the Philippines. Social Indicators Research, 129(2), 863-891. https://doi.org/10.1007/s11205-015-1145-9.

McKenna, T. M. (1998). Muslim rulers and rebels: Everyday politics and armed separatism in the southern Philippines, Comparative studies on Muslim societies. Berkeley: University of California Press.

Murshed, S. M., \& Gates, S. (2005). Spatial-horizontal inequality and the Maoist insurgency in Nepal. Review of Development Economics, 9(1), 121-134. https://doi.org/10.1111/j.1467-9361.2005.00267 .X.

Niño-Zarazúa, M., Roope, L., \& Tarp, F. (2017). Global inequality: Relatively lower, absolutely higher. Review of Income and Wealth, 63(4), 661-684. https://doi.org/10.1111/roiw.12240. 
Østby, G. (2008). Polarization, horizontal inequalities and violent civil conflict. Journal of Peace Research, 45(2), 143-162. https://doi.org/10.1177/0022343307087169.

Posner, D. N. (2004). Measuring ethnic fractionalization in Africa. American Journal of Political Science, 48(4), 849-863.

Rawls, J. (1971). A theory of justice. Cambridge, Mass.: Belknap Press of Harvard University Press.

Reyes, C. M., Tabuga, A. D., Asis, R. D., \& Datu, M. B. G. (2012). Poverty and agriculture in the Philippines: Trends in income poverty and distribution. PIDS Discussion Paper Series 2012 (9).

Rodriguez, E. R. (1998). International migration and income distribution in the Philippines. Economic Development and Cultural Change, 46(2), 329-350. https://doi.org/10.1086/452341.

Roemer, J. E. (1998). Equality of opportunity. Cambridge, Mass.: Harvard University Press.

Sen, A. (1987). Tanner lectures in human values and the standard of living. Cambridge: Cambridge University Press. https://doi.org/10.1017/CBO9780511570742.

Sidel, J. T. (1999). Capital, coercion, and crime: Bossism in the Philippines. Vol. East-West Center series on contemporary issues in Asia and the Pacific. Stanford, Calif: Stanford University Press.

Sidel, J. T. (2014). Economic foundations of subnational authoritarianism: Insights and evidence from qualitative and quantitative research. Democratization, 21(1), 161-184. https://doi.org/10.1080/13510 347.2012 .725725 .

Stewart, F. (2002). Horizontal inequalities: A neglected dimension of development. Queen Elizabeth House Working Paper Series.

Stewart, F. (2010). Horizontal inequalities as a cause of conflict. World Development Report Background Paper.

Stewart, F., \& Langer, A. (2006). Horizontal inequalities: Explaining persistence and change. Paper presented at the Poverty Reduction, Equity, and Growth: New Issues and Findings, Kiel, Germany.

Wucherpfennig, J., Weidmann, N. B., Girardin, L., Cederman, L.-E., \& Wimmer, A. (2011). Politically relevant ethnic groups across space and time: Introducing the GeoEPR dataset. Conflict Management and Peace Science, 28(5), 423-437. https://doi.org/10.1177/0738894210393217. 